\title{
A cultura como chave para a dependência da trajetória na teoria institucionalista de Douglas North
}

Culture as a key to path dependence in Douglas North's institutional theory

Eduardo José Monteiro da Costa (1)

(1) Universidade Federal do Pará

\section{Abstract}

The theory of institutions and institutional change developed by Douglass North reserves a special role for culture, thus signaling a set of strategic research guidelines in some areas of knowledge: economic and development theory; economic historiography; regional/local development; planning, regulation, management and evaluation of public policies. This paper therefore presents in its concluding part a purposeful research agenda from North's seminal contribution. However, before preparing the ground for the achievement of the delineated objective, it presents the fundamental concepts of the author's theory of institutions and institutional change, establishing elements of structural analytical connectivity (institutions, organizations, institutional matrix and path dependence). It then presents the importance of culture in its theoretical construct, especially as the key to understanding the path dependence.

\section{Keywords}

culture, path dependence, development, theory of institutions, Douglass North.

JEL Codes B25, B52.

\section{Resumo}

A teoria das instituições e da mudança institucional desenvolvida por Douglass North reserva um papel especial para a cultura, sinalizando, com isso, um conjunto de diretrizes estratégicas de pesquisas em algumas áreas do conhecimento: teoria econômica e do desenvolvimento; historiografia econômica; desenvolvimento regional/local; planejamento, regulação, gestão e avaliação de políticas públicas. Este artigo, portanto, apresenta em sua parte conclusiva uma agenda propositiva de pesquisas a partir da contribuição seminal de North. Todavia, antes, preparando o terreno para o alcance do objetivo delineado, apresenta os conceitos fundamentais da teoria das instituições e da mudança institucional do autor, estabelecendo elementos de conectividade analítica estrutural (instituições, organizações, matriz institucional e dependência da trajetória). Em seguida, apresenta a importância da cultura em seu constructo teórico, principalmente como a chave para a compreensão da dependência de trajetória.

\section{Palavras-chave}

cultura, dependência de trajetória, desenvolvimento, teoria das instituições, Douglass North.

Códigos JEL B25, B52. 


\section{Introdução}

De que forma a cultura de uma sociedade influencia a sua trajetória de desenvolvimento? Afinal, existem culturas indutoras do desenvolvimento e culturas indutoras do subdesenvolvimento? Durante muito tempo ignorada nos estudos do desenvolvimento econômico, ao menos pelo mainstream, em especial por sua difícil modelagem, a cultura passa a ocupar papel importante como fator explicativo para o sucesso ou o fracasso de países, regiões e cidades na matriz teórica derivada da Nova Economia Institucional (NEI), sobretudo, em função das contribuições de Douglass North.

Dentro de seu modelo analítico, os aspectos culturais acabam dando conformação às diversas instituições da sociedade, entendidas no contexto contemporâneo como o conjunto de normas ou regras, formais e informais, que governam as interações sociais. A partir dessa constatação, é dado um destaque para o papel das instituições no que se refere à modelagem ou não de um ambiente adequado ao processo de desenvolvimento.

Segundo essa visão, a mediação entre instituições e desenvolvimento é feita pelos custos de transação e de acesso às informações, conceitos difundidos pelo institucionalismo contemporâneo que parte do pressuposto de que operações como comprar, vender, estabelecer contratos e exigir o seu cumprimento - ou seja, as transações de que depende a vida material da sociedade - são fundamentais na determinação dos custos de funcionamento de um sistema econômico. Dessa forma, para a diminuição desses custos sociais as condutas dos agentes têm de ser minimamente previsíveis, portanto, estabilizadas. Para isso, as instituições têm o seu papel realçado na medida em que cumprem a função de reduzir riscos e incertezas, incentivando ações humanas coordenadas e adequadas. ${ }^{1}$ Ademais, é o ambiente institucional que molda as diversas organizações que conformam determinada sociedade, estando inclusas nessas organizações as empresas,

1 Conforme destaca Abramovay (2001, pp. 168-169): "O subdesenvolvimento consiste, antes de tudo, num ambiente social em que a cooperação humana inibe a inovação, apoia-se em vínculos hierárquicos localizados e bloqueia a ampliação do círculo de relações sociais em que se movem as pessoas. É exatamente por isso que o segredo do desenvolvimento não reside em dons naturais, na acumulação de riqueza, nem mesmo nas capacidades humanas, mas nas instituições, nas formas de coordenar a ação dos indivíduos e dos grupos sociais (...). O que caracteriza o subdesenvolvimento é um conjunto de instituições - isto é, de regras do jogo, de normas e valores que orientam a conduta do dia a dia, de orientações que reduzem a incerteza dos indivíduos - que dissociam o trabalho do conhecimento, que dificultam o acesso à terra e que bloqueiam a inovação." 
que serão, consequentemente, eficientes ou ineficientes, competitivas ou não, dependendo diretamente do ambiente institucional de seu entorno (Storper, 1999).

Contudo, em que pese o interesse ascendente pelo tema das instituições na análise do desenvolvimento, como pode ser percebido pela crescente vascularização do debate originado de obras como North (1990), Chang (2004) e Acemoglu e Robinson (2012), a análise dos impactos da cultura na trajetória das sociedades por meio de uma perspectiva (neo)institucionalista ainda é um campo relativamente pouco estudado. Forçoso reconhecer que no Brasil alguns trabalhos contribuíram para a disseminação da teoria neoinstitucionalista de North sem, entretanto, entrarem no detalhamento dos aspectos culturais, com destaque para: Gala (2003a; 2003b; 2001), Fiani (2003), Lopes (2013) e Simões (2014). Azevedo (2015) foi o único trabalho que se deteve no esforço de entender o papel da cultura na teoria neoinstitucionalista de North, tendo, porém, apresentado uma análise com viés muito mais antropológico do que econômico.

Neste ponto, é de bom alvitre alertar que estamos adentrando em um campo multidisciplinar eivado de polêmicas conceituais. Porém, não é intenção mapear as divergências existentes e nem explorar a polissemia conceitual do termo cultura. Isso não cabe no objeto deste artigo, sendo um trabalho de fôlego para além do que está proposto.

Em que pese isto, partimos de uma definição de cultura, em termos puramente subjetivos, como valores, atitudes, crenças, orientações e pressupostos subjacentes que predominam entre os membros de uma sociedade e que orientam as suas ações (Huntington, 2004; Landes, 2004; Porter, 2004). Dento da cultura, existe, ainda, aquilo que Porter (2004, p. 53) chama de "cultura econômica", que pode ser definida como "(...) as crenças, as atitudes e os valores que são relevantes para as atividades econômicas de indivíduos, organizações e outras instituições". Em essência, a argumentação de Porter (2004) indica que atitudes, valores e crenças explicam em certa medida as notáveis diferenças de prosperidade econômica entre estados e regiões, praticamente em todos os países. Ademais, enfatiza que a história deixa uma marca profunda na cultura econômica de uma sociedade; uma visão que dialoga centralmente com o conceito de dependência de trajetória de North.

É com base nessa percepção que este artigo se propõe a delinear a teoria das instituições e da mudança institucional desenvolvida por Douglass 
North, por meio de uma análise temporal progressiva de diversas de suas obras, enfocando, sobretudo, o papel ocupado pela cultura como fator explicativo das trajetórias de longo prazo das sociedades. Espera-se, dessa forma, suprir uma lacuna, que ainda permanece no espectro acadêmico, que é a análise do papel da cultura no conjunto teórico neoinstitucionalista de Douglas North. Ao mesmo tempo, espera-se instrumentalizar uma discussão mais ampla sobre a relação entre cultura e desenvolvimento.

Para isso, o presente artigo está dividido em três partes, além desta breve introdução. A primeira apresenta os conceitos fundamentais de sua teoria, estabelecendo elementos de conectividade estrutural (instituições, organizações, matriz institucional e dependência da trajetória). A segunda apresenta a importância da cultura em seu constructo teórico, principalmente como a chave para a compreensão da dependência de trajetória. A parte conclusiva está reservada para o delineamento de um conjunto de diretrizes de pesquisas que podem ser adotadas a partir do estado da arte alcançado pela teoria das instituições e da mudança institucional de Douglass North, em especial no que se refere ao papel desempenhado pela cultura na dinâmica de desenvolvimento das sociedades.

\section{Instituições e mudança institucional: a teoria con- solidada em Douglass North}

A NEI impactou decisivamente os estudos no campo da teoria, historiografia e desenvolvimento econômico. Não por acaso, Douglass North, considerado uma das principais referências dessa escola de pensamento, foi agraciado, em função de sua contribuição nesse campo do conhecimento, em 1993 com o Prêmio Nobel de Economia.

Nascido em Cambridge, Massachusetts, no ano de 1920, North concluiu o doutorado em Economia na Universidade da Califórnia (Berkeley) em 1952. Lecionou na Universidade do Estado de Washington (Seattle) de 1950 a 1983, quando assumiu a titularidade da cátedra Henry R. Luce of Law and Liberty no Departamento de Economia da Universidade Washington, em St. Louis (Missouri), ocupando-a até o seu falecimento em novembro de 2015, aos 95 anos.

Ao longo das décadas nas quais se debruçou sobre a análise da historiografia econômica, North distanciou-se progressivamente da Cliometria 
estabelecendo críticas importantes a elementos dos corpos analíticos do mainstream da teoria econômica ortodoxa,${ }^{2}$ das teorias do crescimento e da teoria do desenvolvimento.

De acordo com North (1994b) a Teoria Neoclássica não consegue explicar com eficiência os motivos que levam as diferentes performances das economias ao longo do tempo. Possui limitações importantes em seus pressupostos como a suposição de que as trocas ocorrem em um mundo sem fricções, sem custos de transação, ${ }^{3}$ com os direitos de propriedade perfeitamente especificados e com racionalidade ilimitada, implicando informações fluidas e de conhecimento pleno por parte dos agentes (Robles, 1998; Azevedo, 2015).

Para além das críticas elencadas em North e Thomas (1973) sobre as tradicionais teorias do crescimento, apontando que estas confundem as consequências do processo com as causas, North (1981; 1990) estabelece críticas ao princípio racional e maximizador do homo oeconomicus, afirmando que altruísmo, ideologias, questões éticas, morais, políticas e religiosas possuem papel destacado na motivação do comportamento dos agentes.

Nem mesmo a teoria do desenvolvimento foi poupada de suas críticas. Segundo ele, mesmo depois de quarenta anos de esforços, as disparidades no desempenho das economias e a sua persistência ao longo do tempo não foram satisfatoriamente explicadas, sobretudo devido à omissão em suas análises a respeito da natureza da coordenação e da cooperação humanas (North, 1990).

Essa percepção sobre a inconsistência dada pela teoria aos problemas

2 Conforme North (1994b, pp. 567-568): "A teoria neoclássica é simplesmente uma ferramenta inadequada para analisar e prescrever políticas que induzem o desenvolvimento. Ela se preocupa com o funcionamento dos mercados, mas não sobre como eles se desenvolvem. Como se pode prescrever políticas sem entender o desenvolvimento das economias? Os próprios métodos usados pelos economistas neoclássicos se impuseram sobre o assunto e agiram contra esse desenvolvimento. Essa teoria na forma original, que lhe dava precisão matemática e elegância, modelou um mundo estático e sem fricções. Quando aplicado à história e ao desenvolvimento econômico, concentrou-se no progresso tecnológico e, mais recentemente, no investimento em capital humano, mas ignorou a estrutura de incentivos incorporados nas instituições que determinavam o grau de investimento social nesses fatores. $\mathrm{Na}$ análise do desempenho econômico ao longo do tempo, ele continha duas premissas errôneas: a) que as instituições não importam; e b) que o tempo não importa."

3 Conforme North (1994b, p. 569): "Foi Ronald Coase (1960) quem estabeleceu a relação fundamental entre instituições, custos de transação e teoria neoclássica. $\mathrm{O}$ resultado neoclássico de mercados eficientes somente prevalece quando as transações ocorrem sem custo de negociação. Somente sob condições de negociação sem custo os atores alcançarão a solução que maximiza a renda agregada, independentemente dos arranjos institucionais. Quando a negociação tem um custo, as instituições se tornam importantes. E negociar implica um custo." 
de coordenação e cooperação humanas levou North, da mesma forma, a questionar o modelo da Teoria dos Jogos que, segundo a sua opinião, não parte de uma hipótese de comportamento humano realista. Em sua perspectiva, o comportamento humano, conforme já destacado, é muito mais complexo do que assume a função de utilidade dos modelos econômicos convencionais (North, 1990). ${ }^{4}$

A partir dessas constatações e partindo da premissa de que o mundo econômico é não ergódico - portanto passivo de mudanças contínuas, inusitadas e atípicas, no qual os agentes precisam de um amplo esforço cognitivo para a compreensão dos fenômenos econômicos e sociais (North, 2005; Lopes, 2013; Azevedo, 2015) -, e, também, com o objetivo de aperfeiçoar o instrumental analítico ortodoxo, ${ }^{5}$ North lançou-se no desafio de consolidar uma teoria das instituições e da mudança institucional que lhe permitisse obter melhor resultado na análise da dinâmica do desenvolvimento por meio de uma perspectiva histórica. É, nesse sentido, a partir do livro Instituições, mudança institucional e desempenho econômico, publicado originariamente em língua inglesa no ano de 1990, que o aporte analítico de Douglass North sobre o papel das instituições e da mudança institucional no desenvolvimento econômico alcança maior nível de maturidade. ${ }^{6}$

North inicia o seu discurso por ocasião do recebimento do Prêmio Nobel de Ciência Econômicas, proferido em Estocolmo na Suécia no dia 9 de dezembro de 1993, afirmando (North, 1994b, p. 567):

A história econômica trata sobre o desempenho das economias ao longo do tempo. O objetivo das investigações neste campo não é somente permitir que o passado econômico se torne mais claro, mas também contribuir para a teoria econômica proporcionando um marco analítico que nos permita compreender a mudança econômica.

Seguindo esse desiderato, o ponto de partida de seu modelo é o axioma de que as instituições e a estrutura produtiva herdadas por meio de processos

4 Para o aprofundamento a respeito das críticas em relação à Teoria dos Jogos, recomenda-se, especificamente, o Capítulo 2 de North (1990).

5 De acordo com Robles (1998), o modelo analítico desenvolvido por Douglass North é uma modificação da Teoria Neoclássica na medida em que aceita a hipótese fundamental da escassez e as ferramentas da microeconomia ortodoxa, porém, modifica a hipótese de racionalidade ao assumir o pressuposto da informação incompleta e modelos subjetivos da realidade, bem como os retornos crescentes, característico da análise institucionalista.

6 De acordo com Robles (1998), o livro Instituições, mudança institucional e desempenho econômico explica com maior rigor e detalhe, do que nos estudos anteriores, três aspectos fundamentais de seu marco analítico: o que são as instituições; como se diferenciam as instituições das organizações; e como as instituições influem nos custos de transação e produção. 
históricos singulares geram dinâmicas socioeconômicas diversificadas entre nações. Isso significa que o desenvolvimento econômico é um fenômeno eminentemente institucional, resultante de complexas interações entre forças econômicas, políticas e culturais da qual fazem parte distintos arranjos institucionais, que conferem diferenças nas trajetórias de desenvolvimento, bem como na forma de organização das diversas organizações da sociedade. Nesse sentido, o sucesso ou o fracasso das nações decorrem de sua formação histórica e da forma como as suas instituições foram criadas e/ou evoluíram.

Em suma, quando North formula a questão central de sua pesquisa por que algumas nações adentram em um caminho de prosperidade enquanto outras permanecem na pobreza e na miséria? -, ele encontra a resposta nas instituições e nas organizações que as sociedades constroem ao longo de sua história (North, 1994b). É seguindo essa senda que passamos a apresentar os conceitos fundamentais de sua teoria: instituições, matriz institucional, organizações, dependência de trajetória (path dependence) e ruptura institucional.

\subsection{Instituições}

As instituições são apresentadas como normas socialmente construídas ("regras do jogo"), gozando de aceitação geral pelos membros de um grupo social, que impõem restrições formais e/ou informais e que moldam o processo de interação, ao mesmo tempo que estruturam incentivos na troca humana, sejam estes de ordem política, social ou econômica. ${ }^{7}$ Ao fazerem isso as instituições reduzem a incerteza ${ }^{8}$ na medida em que conferem uma estrutura previsível de ação por meio da coordenação das expectativas divergentes, criando padrões de comportamento duráveis e rotineiros que estabelecem limites para o conjunto de escolhas dos agentes (North, 1990).

7 Logo na abertura do Capítulo 1, North (2018, p. 13) declara: "As instituições são as regras do jogo em uma sociedade ou, em definição formal, as restrições concebidas pelo homem que moldam a interação humana." Essa visão retorna em seu discurso em Estocolmo, de acordo com North (1994b, p. 571): "A interação entre instituições e organizações conforma a evolução institucional de uma economia. Se as instituições são as regras do jogo, as organizações e seus empresários são os jogadores."

8 Para North (2018, p. 50): "(...) as incertezas decorrem de incompletude das informações a respeito da conduta dos outros indivíduos no processo de interação humana." 
Conforme North (1991, p. 97):

As instituições são restrições criadas pelos homens que estruturam a interação política, econômica e social. Elas consistem em restrições informais (sanções, tabus, costumes, tradições e códigos de conduta) e regras formais (constituições, leis, direitos de propriedade). Ao longo da história, instituições foram criadas por seres humanos para criar ordem e reduzir a incerteza nas trocas. Juntamente com as restrições comuns da economia, elas definem o conjunto de opções e, portanto, determinam os custos de transação e produção e, portanto, a lucratividade e a viabilidade de se envolver na atividade econômica. Elas evoluem gradualmente, conectando o passado com o presente e o futuro; a história em consequência é, em grande parte, uma história da evolução institucional, na qual o desempenho histórico das economias só pode ser compreendido como parte de uma história sequencial. As instituições fornecem a estrutura de incentivos de uma economia; à medida que essa estrutura evolui, ela molda a direção da mudança econômica em direção ao crescimento, estagnação ou declínio.

Em Estocolmo, North (1994b, p. 569) reforçou esse entendimento:

As instituições estabelecem os limites concebidos pelo homem para estruturar sua própria interação. Estão constituídas por restrições formais (regras, leis, constituições), restrições informais (padrões de comportamento, convenções, códigos de conduta autoimpostos) e suas respectivas características de aplicação. Juntas definem a estrutura de incentivos das sociedades e especificamente das economias.

As instituições reduzem - juntamente com a tecnologia empregada - os custos de transação e transformação, bem como o de acesso às informações, envolvidos na atividade humana. Conforme North (2018, p. 197):

As instituições proporcionam a estrutura básica por meio da qual, no decorrer da história, os seres humanos têm gerado ordem e buscado reduzir a incerteza na troca. Juntamente com a tecnologia empregada, elas determinam o custo de transação e transformação e com isso a viabilidade e o proveito de participar da atividade econômica.

Porém, em que pese o principal papel das instituições seja o de reduzir a incerteza, estabelecendo uma estrutura estável para a interação humana, estas não são necessariamente eficientes do ponto de vista social, podendo, consequentemente, os custos de transação, produção e acesso as informações diferirem substancialmente entre as sociedades em decorrência de suas diferentes estruturas institucionais.

\subsection{Matriz institucional, organizações e mudança institucional}

Conforme exposto, existe um caráter histórico nas trajetórias das sociedades que deriva da forma como as suas matrizes institucionais foram conformadas e evoluíram. Consequentemente, a compreensão das trajetórias de desenvolvimento das nações depende da investigação de sua matriz institu- 
cional e, para isso, torna-se necessária a análise da conformação das regras e normas, formais e informais, que a compõem, formando uma rede interligada que, sob variadas combinações, moldam o conjunto de escolhas dos agentes em múltiplos contextos, bem como das instituições que garantem a sua aplicação (enforcement). Essa hipótese leva ao corolário de que, de um lado, o subdesenvolvimento é resultado de instituições socialmente ineficientes e, de outro, somente com uma mudança institucional países subdesenvolvidos conseguiriam romper com a sua trajetória de subdesenvolvimento.

A mudança institucional, ao definir o modo como as sociedades evoluem ao longo do tempo, pode ser até mesmo mais importante para o desenvolvimento, ao estimular o capital físico e humano, do que o acesso a inovações tecnológicas (Gala, 2003a; North, 1990). Nessa análise, as organizações - entendidas como grupos de indivíduos unidos por um propósito comum - inserem-se como elementos dinâmicos do modelo. ${ }^{9}$ Ao mesmo tempo que são influenciadas pelo ambiente institucional na qual estão inseridas, as organizações influenciam a transformação desse ambiente, ao perseguirem os seus objetivos, num processo que molda a evolução institucional da sociedade. ${ }^{10}$ Em síntese, se as instituições são as "regras do jogo", as organizações são os jogadores (North, 1990; 1994a; 1994b).

\subsection{Dependência de trajetória}

North (1990) ao firmar a compreensão de que as instituições são dependentes de suas trajetórias prévias - portanto "portadoras da história", na medida em que apresentam fortes relações com suas configurações historicamente herdadas (Strachman, 2000) ${ }^{11}$ - estabelece a matriz institucional

9 De acordo com North (2018), as organizações incluem órgãos políticos (partidos políticos, Câmaras, Senados, Conselhos e agências reguladoras), corpos econômicos (empresas, sindicatos, fazendas, cooperativas e associações patronais), corpos sociais (igrejas, clubes, sociedades filantrópicas e culturais) e órgãos educacionais (escolas, universidades e centros de formação profissional).

10 Azevedo (2015), estabelecendo como referência North (1990), destaca que enquanto as instituições estabelecem as oportunidades em uma sociedade, as organizações são criadas para tirarem proveito dessas oportunidades.

11 É importante neste ponto abrir um parêntese para fazer justiça destacando que Douglass North não foi o pioneiro na apresentação dessa compreensão histórica da conformação das instituições, Thorstein Veblen, um dos precursores da Escola Institucionalista Americana, já expunha em seu trabalho de 1899, The Theory of the Leisure Class: An Economic Study of Institutions, que as instituições e as tecnologias uma vez adotadas poderiam gerar um efeito de 
de uma sociedade como o elo de ligação entre o passado e o presente, e como condicionante do futuro por meio de uma dependência de trajetória, moldada por meio da interação entre instituições e organizações. Isso realça a importância para a historiografia econômica da compreensão das sequências temporais de eventos e processos sociais, bem como sobre o meio em que esses processos ocorreram e que permitiram a geração de determinada percepção pelos indivíduos, constrangendo-os, ou não, a optarem pelo aproveitamento de "janelas de oportunidades" disponíveis. ${ }^{12}$

O conceito de dependência de trajetória surge, assim, como uma explicação que permite observar a influência do passado sobre o presente e deste sobre o futuro, possibilitando o entendimento das diferenças de desenvolvimento entre países, regiões e cidades, decorrente de processos de autorreforço de suas trajetórias históricas. Conforme North (1990, pp. 98-99):

A dependência de trajetória é uma maneira de restringir conceitualmente o conjunto de opções e vincular a tomada de decisões ao longo do tempo. Não é uma história de inevitabilidade em que o passado prediz exatamente o futuro. (...) Uma vez que um caminho de desenvolvimento é definido em um curso especifico, as externalidades da rede, o processo de aprendizagem das organizações e a modelagem subjetiva das questões derivadas historicamente reforçam o curso.

Assim, uma vez definido um caminho, há a atuação de mecanismos autorreforçantes que fazem com que a matriz institucional fique "trancada" (lock in) em uma trajetória, mutável apenas por meio de uma ruptura institucional. E, caso ocorra por qualquer motivo uma mudança nas estruturas institucionais, altera-se a percepção por parte dos agentes da matriz de incentivos e incertezas, bem como a predisposição à cooperação e os custos de transação sobre o ambiente (North, 2005).

\section{A cultura como chave para a compreensão da de- pendência de trajetória}

A teoria das instituições e da mudança institucional de North amadureceu ao longo de vários anos de pesquisas e de diversos trabalhos. ${ }^{13} \mathrm{O}$ livro retroalimentação e reforço de um padrão institucional e tecnológico (Hodgson, 1994). 12 North (1990) utiliza o conceito de dependência de trajetória para explicar a diferenças socioeconômicas entre os Estados Unidos e a América Latina, posto que o processo de formação institucional distinto entre as colônias americanas acabou por determinar desempenhos econômicos diferentes. Mais à frente entraremos, mesmo que superficialmente, nesse debate. 13 Conforme Gala (2001), o escopo analítico de North foi consolidado a partir de várias in- 
Instituições, mudanças institucionais e desempenho econômico, publicado originalmente em língua inglesa no ano de 1990, pode ser considerado como o marco temporal que separa o North em amadurecimento teórico (décadas de 1970 e 1980) do North com uma visão teórica mais consolidada e com concatenamentos analíticos mais complexos entre os seus conceitos fundamentais (décadas de 1990 e 2000).

\subsection{Décadas de 1970 e 1980: um teórico em amadurecimento}

No processo de crescente afastamento da Cliometria, North e Thomas (1973), ao sinalizarem que diferentes processos culturais poderiam resultar em diferentes histórias econômicas, estabeleceram insights que levariam North a paulatinamente ampliar a sua análise sobre a relação entre as instituições informais e o desenvolvimento. ${ }^{14}$ Em que pese isso, a noção de indivíduo assumida em boa parte do livro ainda era muito próxima da perspectiva neoclássica, sendo este ainda visto como um átomo social que estabelecia o seu comportamento de forma independente de seu entorno social (Azevedo, 2015).

Em North (1981) é possível observar uma mudança nessa premissa comportamental dos indivíduos, ${ }^{15}$ sobretudo, com a introdução em sua análise da ideologia, que funcionaria como elemento simplificador dos processos decisórios, conferindo uma visão específica de mundo ao indivíduo tomador de decisão, e servindo como fator explicativo para a compreensão de estruturas políticas e econômicas ineficientes. Conforme North (1981, p. 7): “(...) a persistência de estruturas políticas e econômicas ineficientes, por

fluências. $O$ conceito de custos de transação apropria-se de Ronald Coase, a ideia de incerteza de Friedrich Hayek e Frank Knight, o insight da racionalidade limitada de Hebert Simon, o conceito de trajetória dependente de Brian Arthur e Paul David e, de sua própria autoria, uma visão sobre a ideologia e o Estado.

14 Um exemplo claro disso é quando North e Thomas (1973) reconhecem a influência de questões religiosas no processo de consolidação do mercado capitalista, citando o problema da condenação dos empréstimos a juros pela Igreja Católica por meio do Papa Clementino $\mathrm{V}$, no século XIV; ao passo que reconhecem o estímulo favorável ao desenvolvimento do capitalismo advindo do cristianismo reformado, citando como exemplo o ato de Charles $\mathrm{V}$ (Holanda) que em 1543 liberou o empréstimo com cobrança de juros, segundo os autores, essencial para a dinamização do mercado de capitais holandês.

15 A teoria da ideologia, inserida por North (1981) em sua análise das instituições, altera a concepção de racionalidade do indivíduo. A esse respeito, ver Azevedo (2015), em especial o Capítulo 6. 
sua vez, torna a existência de ideologias concorrentes uma questão crítica na compreensão da história econômica."

Ademais, a combinação das regras constitucionais com os códigos de comportamentos culturais subjacentes, ao mesmo tempo que dá estabilidade às instituições, torna qualquer dinâmica de mudança demorada e, em regra, apenas incremental. Ou seja, ideologia, normas e convenções sociais, bem como códigos de conduta ética e moral, passaram a ser elementos importantes na análise por interferirem na esfera comportamental dos indivíduos e darem legitimidade, estabilidade e ordem à vida social. ${ }^{16}$ No limite, sem os constrangimentos impostos por questões ideológicas, os custos de enforcement seriam inviáveis para às organizações.

\subsection{Décadas de 1990 e 2000: uma visão consolidada}

Em North (1990), e em alguns trabalhos posteriores, a partir da introdução do conceito de racionalidade limitada, é possível notar significativo avanço na compreensão da dinâmica institucional decorrente do tratamento da cultura como chave para a compreensão da dependência de trajetória. ${ }^{17}$ A partir desse ponto, em vez de proceder a uma análise cronológica de seus trabalhos, optamos - posto entendermos que para efeito de análise e sistematização é mais objetivo e profícuo - por buscar edificar sua visão sobre o papel da cultura no desenvolvimento econômico com base em seus trabalhos mais recentes (décadas de 1990 e 2000).

No conjunto teórico desenvolvido por Douglass North o mundo econômico é não ergódico, apresentando mudanças contínuas, inusitadas e atípicas, e os indivíduos, por meio de modelos mentais preexistentes, processam informações incompletas, num esforço cognitivo de compreensão dos fenômenos econômicos e sociais, que os auxiliam no entendimento do ambiente ao mesmo tempo que determinam o seu comportamento social,

16 Rutherford (1994) estabelece uma crítica à tentativa de inserção da ideologia por North (1981), afirmando que, em que pese a tentativa, o autor não conseguiu apresentar uma teoria da ideologia que explicasse a estabilidade e a mudança institucional. Segundo Azevedo (2015), em diversas passagens fica clara a confusão do autor entre ideologia e cultura, aparentemente tratadas por ele como sinônimas, ademais, afirma que a forma como North (1981) trabalha o conceito de ideologia é exógena e instrumental.

17 Para maiores detalhes sobre a introdução do conceito de racionalidade limitada, recomendamos ver Azevedo (2015). 
nem sempre movidos por impulsos maximizadores, mas, em muitos casos, pelo altruísmo e por restrições autoimpostas (North, 1990; 2005). Nesse sentido, as instituições - por meio de informações socialmente transmitidas em determinado contexto cultural - estabelecem mecanismos de incentivos ou restrições nas decisões dos indivíduos e das organizações (North, 1993).

Conforme North (1994b, pp. 572-573):

É necessário desmontar o pressuposto de racionalidade subjacente na teoria econômica para enfocar construtivamente a natureza da aprendizagem humana. A história demonstra que as ideias, as ideologias, os mitos, os dogmas e os preconceitos importam, e uma compreensão da maneira como evoluem é necessária para avançar ainda mais no desenvolvimento de uma estrutura que ajude a explicar a mudança social.

North, em diversos trabalhos, cita a ideologia como um elemento explicativo importante, sobretudo para a legitimação da ordem social e das instituições criadas (Azevedo, 2015). Em função disso, ele sente a necessidade de melhor conceituar o termo. Para North (1990), ideologia é a percepção subjetiva (modelo subjetivo) que um indivíduo ou grupo social possui da realidade, e que utiliza para explicar o seu funcionamento (modelo normativo) e estabelecer seus padrões de interação social.

Em Estocolmo, North (1994b, p. 574) novamente apresentou o conceito: "As ideologias são estruturas compartilhadas de modelos mentais que agrupam indivíduos e que oferecem tanto uma interpretação do ambiente e como uma diretriz de como esse ambiente deve ser ordenado."

Em Denzau e North (1994) encontramos uma definição similar. Mas, também, encontramos elementos que nos permitem sinalizar para a compreensão que ele (North) adota de cultura, ainda que não o façam de forma explícita. Neste artigo, os autores ao se proporem a elaborar um ensaio, ainda que o chamem de preliminar, sobre as implicações da maneira pelas quais os seres humanos ordenam e estruturam o seu ambiente, destacam que é necessário abrir a "caixa-preta" da racionalidade e encontrar o incompleto e complexo mundo da ciência cognitiva.

Neste mundo as ideias importam, e o caminho pelo qual elas evoluem, e são comunicadas, é a chave para a construção de uma teoria capaz de ampliar a compreensão do desempenho das sociedades ao longo do tempo, sobretudo, porque é com base nas ideias que toda uma estrutura de incentivos (econômicos e sociais) é conformada. As ideias expressam ideologias e modelos mentais compartilhados, e estes fornecem os elementos 
necessários para a ação e a tomada de decisão em um ambiente complexo, eivado de incertezas.

Denzau e North (1994) definem as ideologias como uma estrutura compartilhada de modelos mentais que indivíduos pertencentes a determinados grupos sociais utilizam para interpretar o ambiente e prescrever a sua estruturação. Nesse sentido, os indivíduos não agem de acordo com a racionalidade substantiva, mas as suas ações são fortemente influenciadas por elementos cognitivos de seus modelos mentais.

Assim, indivíduos com formação cultural comum apresentam um processo de aprendizagem social similar e formam modelos mentais, ideologias e instituições razoavelmente convergentes; ao passo que indivíduos com experiências de aprendizagens diferentes formam diferentes teorias (modelos e ideologias) para interpretar o ambiente e tomar decisões, ou seja, agem de forma diversa. Em síntese, enquanto os modelos mentais são representações internas que o sistema cognitivo usa para interpretar o ambiente, as instituições são os mecanismos externos que os indivíduos criam para estruturar e ordenar este ambiente. Logo, ideologias e instituições podem ser vistas como classes de modelos mentais compartilhados.

Destarte, a compreensão da conformação e dinâmica de funcionamento desses modelos mentais é uma agenda de importância crucial para a compreensão do desenvolvimento humano e da sociedade. Conforme enfatizam Denzau e North (1994, p. 5):

Os modelos mentais criados pela mente e as instituições criadas pelos indivíduos são ambos essenciais para compreender a maneira que os seres humanos estruturam o seu ambiente e estabelecem relações com ele. A compreensão de como esses modelos evoluem e se relacionam é o passo mais importante que a pesquisa em ciências sociais pode dar para substituir a caixa-preta da suposição da "racionalidade" usada nos modelos econômicos e de escolha racional. Precisamos desenvolver uma estrutura analítica que nos permita entender e modelar os constructos mentais compartilhados que orientam as escolhas e moldam a evolução dos sistemas politico-econômicos e das sociedades.

Tentando contribuir para essa agenda, os autores destacam que a estrutura dos modelos mentais é derivada de um processo de aprendizado cultural, ou seja, de experiências individuais vivenciadas em determinado ambiente linguístico e sociocultural. É nesse sentido que a cultura, por permitir a redução de divergências, torna-se um elemento determinante para a formação dos modelos mentais compartilhados e, consequentemente, das ideologias e das instituições. Conforme Denzau e North (1994, p. 15): 
O patrimônio cultural fornece um meio para reduzir a divergência nos modelos mentais que as pessoas de uma sociedade possuem e também constitui um meio para a transferência intergeracional de percepções unificadoras. Podemos pensar na cultura como uma encapsuladora de experiências de gerações passadas de qualquer grupo cultural em particular. Com a diversidade de experiências humanas em diferentes ambientes, existe uma grande variedade de padrões de comportamento e pensamento.

Resta claro que tanto as ideologias quanto as instituições devem ser compreendidas como partes da cultura de uma sociedade. Mas, qual é a definição que podemos abstrair de cultura na perspectiva de North?

Apesar de trabalhar com a categoria cultura, North não estabelece uma definição própria dessa categoria. North (1990, p. 37) utiliza-se da definição de Boyd e Richerson (1985, p. 2) que consideram cultura como a “(...) transmissão de uma geração para a seguinte, por meio do ensino e da imitação de conhecimentos, valores e outros fatores que influenciam o comportamento."

Em Denzau e North (1994), conforme já exposto, a cultura pode ser compreendida como uma instituição social fruto da interação humana, que permite a transmissão intergeracional de percepções unificadoras e que, ao mesmo tempo, condiciona o padrão de interação entre os indivíduos. Ou seja, ao mesmo tempo que o indivíduo, a partir de seu modelo mental individual, influencia a dinâmica social mais ampla, por intermédio das organizações das quais participa, ele é, dialeticamente, influenciado pelo modelo mental compartilhado que traz consigo hábitos herdados, pressupostos subjacentes, valores, crenças, orientações e ideologias.

A cultura, portanto, ao afetar a conformação das instituições e da matriz institucional de uma sociedade, influencia decisivamente a sua trajetória por condicionar comportamentos individuais e coletivos dentro de determinados padrões, o que alguns chamam de mecanismos sociais de enforcement. Pode-se afirmar, assim, que existem culturas propícias ou desfavoráveis ao desenvolvimento.

É inegável que a teoria das instituições e da mudança institucional desenvolvida por North reserva um papel especial para a cultura no processo de determinação das trajetórias sociais de longo prazo na medida em que a estrutura que governa a interação social cotidiana, passando por relações familiares, ou mesmo no campo do trabalho e dos negócios, é definida em grande medida por restrições informais, códigos de conduta, normas de comportamento e convenções. Estes, ao mesmo tempo que fazem parte de uma herança cultural, definem a forma como os indivíduos processam 
e utilizam as informações, bem como tomam as suas decisões por meio de seus modelos mentais.

Esses modelos mentais - um constructo advindo das ideias, ideologias e religiões -, ao sustentarem crenças que reduzem as divergências entre os indivíduos e garantirem a transferência intergeracional do conhecimento, acabam estabelecendo o molde sobre o qual são conformadas as economias e as sociedades (North, 1990; 1994b; 2005; Denzau; North, 1994a; Lopes, 2013; Azevedo, 2015). ${ }^{18}$

É em decorrência disso que North (1994b) compreende as instituições como representações da consciência dos indivíduos, expressões dos modelos mentais compartilhados e, portanto, representações externas dos modelos cognitivos individuais, que possuem como finalidade a estruturação e a organização de seu meio através da estabilização das ações e da redução da incerteza.

Para North (2005, p. 162): "A essência da compreensão do papel das instituições em uma sociedade é reconhecer que elas incorporam a intencionalidade de nossa mente consciente." É nesse sentido que North (2003a) destaca que as regras informais acabam se tornando, para a dinâmica das sociedades, até mesmo mais importantes do que as formais. ${ }^{19}$ Exatamente por isso que mudanças culturais evolvendo alterações na cosmovisão dos indivíduos, advindas de alterações na ideologia, crenças, valores e religião, abalam a estabilidade das instituições e tendem a ser importantes vetores de mudanças institucionais (North, 1990; 2005; Robles, 1998). ${ }^{20}$

Conforme afirma Robles (1998, p. 16):

North considera que a cultura é a chave para a compreensão do fenômeno da "dependência de trajetória" [path dependence], quer dizer, para compreender por que é tão difícil que as economias - uma vez encaminhadas por um caminho de crescimento, ou estagnação, ou declive - logrem reverter sua tendência de longo prazo. North explica que a aprendizagem de qualquer geração está

18 Para North (1992), rotinas, costumes, tradições e cultura são termos usados para denotar a persistência de regras ou restrições informais, que incluem: a) convenções que evoluem como soluções para problemas de coordenação e que todas as partes têm interesse em manter; b) normas de comportamento que são padrões de conduta reconhecidos; c) códigos de conduta autoimpostos, como padrões de honestidade ou integridade.

19 Convém, contudo, salientar que para North (2003a), na medida em que as restrições informais conferem determinada estabilidade para as instituições, as mudanças institucionais, quando ocorrem, tendem a ser graduais.

20 North (2005) enfatiza que as crenças religiosas e as ideologias seculares desempenham importante papel nas mudanças sociais, citando como exemplo a ascensão e queda do ideal comunista na URSS. 
fortemente condicionada pelas percepções derivadas da aprendizagem coletiva secular. Assim, a aprendizagem é um processo cumulativo filtrado pela cultura de uma sociedade.

A cultura, dessa forma, torna-se elemento central para explicar a performance econômica e política através do tempo (North, 2005); ${ }^{21}$ e, como mencionado, materializa-se, em última instância, como a chave para a dependência de trajetória, na medida em que os indivíduos ao fazerem as suas escolhas o fazem sob influência de suas crenças, formadas por meio de um processo de aprendizagem cumulativo que é transmitido culturalmente de uma geração para outra. Conforme North (1994b, p. 576): "É a cultura que fornece a chave para a dependência da trajetória - uma noção usada para descrever a poderosa influência do passado no presente e no futuro."

Ainda segundo North (1994b, p. 568):

Ou seja, as crenças que os individuos, os grupos e as sociedades mantêm e mediante as quais determinam suas opções são uma consequência do aprendizado ao longo do tempo - não somente do lapso de vida de um indivíduo ou de uma geração numa sociedade, mas a aprendizagem incorporada em indivíduos, grupos e sociedades que é cumulativa ao longo do tempo e que passa de geração em geração pela cultura de uma sociedade.

Portanto, o processo de aprendizagem social advém das experiências socioculturais vivenciadas pelos indivíduos, algo que é constantemente atualizado a partir de impulsos externos (North, 2005). ${ }^{22}$ Essa visão também está presente em North, Mantzavinos e Shariq (2004) ao enfatizarem que os modelos mentais são dinâmicos e evoluem com o decorrer do tempo como resultado das experiências vivenciadas pelos seres humanos. Quando considerados adequados para a interpretação do ambiente acabam se estabilizando e modelando um "sistema de crenças", porém, quando se mostram inconsistentes acabam revistos e originam um novo sistema de crenças. North, Wallis e Wingast (2006) destacam que as organizações educacionais e religiosas possuem papel privilegiado na conformação das crenças dos indivíduos e, como consequência, na moldagem das organizações.

É em função disso que o foco recai sobretudo no indivíduo como unidade analítica na medida em que a percepção da realidade social acaba

21 North (2005) enfatiza que as crenças dos indivíduos que ocupam posições responsáveis por criar as diretrizes políticas e econômicas são chamadas de crenças dominantes, estas com o tempo são as responsáveis pelo acréscimo gradual a estrutura elaborada das instituições que determinam o desempenho econômico e político.

22 North (2005) considera que a estrutura inicial de aprendizagem é genética, um debate polêmico e que necessita de uma análise mais aprofundada, mas que não é o busílis deste trabalho. 
sendo resultante de um processo de aprendizagem e do modelo cognitivo individual, formado em um contexto específico e derivado das crenças e percepções advindas de uma estrutura institucional, ideológica, educacional e religiosa disseminada na sociedade. ${ }^{23}$

Derivado desse entendimento é possível afirmar que: a) o desempenho econômico de uma sociedade é expressão última de suas instituições, moldadas por um processo histórico através da cultura, das crenças, dos modelos mentais compartilhados e dos modelos cognitivos individuais; b) os modelos mentais condicionam as ações dos indivíduos, e acabam determinando trajetórias sociais dependentes; c) nenhuma mudança institucional ocorre sem o suporte de um sistema de crenças preexistente; d) a determinação causal do desenvolvimento segue, portanto, do nível cognitivo, para o institucional e deste para o econômico (North, 2003a; North; Mantzavinos; Shariq, 2004).

\subsection{A análise historiográfica: uma análise das formações institucio- nais e das mudanças institucionais}

A partir desses pontos emerge um questionamento, é possível ocorrer alteração nas instituições informais? Para North (1990), normas e convenções sociais podem ser alteradas por meio do aprendizado cumulativo ou em decorrência de choques externos, como guerras e desastres naturais, por exemplo.

Isto posto, a partir desse paradigma a análise historiográfica precisa dar mais atenção para o processo de conformação das instituições e para as mudanças institucionais que ocorreram ao longo da história, estabelecendo elementos de análise que permitam explicar as trajetórias sociais de longo prazo com base na conformação das matrizes institucionais das sociedades.

Um exemplo dessa aplicação é a análise que North desenvolve em alguns trabalhos sobre o processo de construção das matrizes institucionais dos Estados Unidos e da América Latina, derivadas de suas metrópoles europeias, para exemplificar a dependência de trajetória advinda de uma

23 Esse modelo de aprendizagem, que pode acontecer em qualquer espaço de interação social, desde o ambiente familiar até qualquer outra organização, é relevante para explicar o funcionamento das economias. 
herança histórico-institucional (North; Thomas, 1973; North, 1989; 1990; 1991; 2003b). ${ }^{24}$

Em sua perspectiva, as colônias inglesas tiveram um desempenho melhor do que as ibéricas (Portugal e Espanha) em razão de terem herdado uma trajetória institucional mais propícia para o desenvolvimento. ${ }^{25}$ Conforme expresso em diversos de seus trabalhos, o processo de ocupação das colônias britânicas ocorreu em um período marcado por intensas disputas entre o poder absolutista inglês e o parlamento, pela cisão com a Igreja Católica e instituição da Igreja da Inglaterra (Anglicana), e pela perseguição aos calvinistas puritanos. Como consequência disso, muitos dos colonizadores migrantes levaram consigo ideais de liberdade política e religiosa, indutoras de um amplo processo de descentralização colonial, participação cívica, construção de um sistema político federalizado, com pesos e contrapesos que garantiam a propriedade privada e a sujeição ao Estado de Direito, e que funcionaram como elementos indutores das atividades comerciais, produtivas e como incentivo à inovação. Com a tentativa da Coroa Britânica de estabelecer impostos sobre as exportações de tabaco das colônias, eclodiu-se a Revolução Americana, a Declaração de Independência e a promulgação da Constituição Americana de 1776.

As colônias ibéricas, por seu turno, herdaram instituições que acabaram moldando uma trajetória distinta, fruto de uma dinâmica específica de suas metrópoles, que vivenciaram conflitos internos pela unificação territorial, expulsão dos mouros e necessidade de centralização do poder em torno das Coroas. Esse processo de centralização burocrática se estendeu para o território colonial, ocasionando inúmeros conflitos pulverizados, que acabaram, especialmente nas colônias espanholas, eclodindo nas guerras pela independência. Para North (1990), em grande parte, essas guerras espelharam uma disputa pelo controle da burocracia estatal entre o poder local e

24 Em trabalho anterior, North e Thomas (1973) já haviam enfatizado que os avanços institucionais que ocorreram na Inglaterra e Holanda antes da Revolução Industrial, que estabeleceram as bases para a superação do conflito entre o crescimento populacional e os limites impostos pelas instituições feudais, ajudam a explicar o avanço de suas economias comparativamente à economia da Espanha e da França. Assim, para os autores Inglaterra e Holanda conseguiram promover mudanças institucionais indutoras de uma trajetória bem-sucedida.

25 North (2018, p. 125): “(...) comparando-se os quadros institucionais que se verificam em países como Estados Unidos, Inglaterra, França, Alemanha e Japão com os casos de países do Terceiro Mundo ou de países com industrialização avançada no passado histórico, evidencia-se que o quadro institucional é a chave do êxito relativo das economias tanto em determinado momento como ao longo do tempo." 
a Coroa Espanhola. Como resultado, as instituições conformadas por essa dinâmica histórica não promoveram, ao contrário do processo desencadeado nas colônias inglesas do Norte, um ambiente de estabilidade institucional, política e jurídica adequada para o desenvolvimento, mas foram indutoras de um processo marcado por: a) um poder político extremamente centralizado, apoiado por uma burocracia civil, militar e religiosa; b) uma dinâmica parlamentar enfraquecida ou inexistente; c) ausência de independência do Poder Judiciário; d) forte interferência do Estado na economia; e) falta de garantia ao direito de propriedade e desrespeito aos contratos; e, f) ausência de adequados mecanismos de incentivos ao setor privado.

North (2003b) destaca que os países latino-americanos, após os seus processos de independência, apesar de terem copiado em grande medida a Constituição dos Estados Unidos e diversas de suas regras de direitos de propriedade, obtiveram resultados diferentes dos alcançados em território Norte-Americano, sobretudo, porque as regras formais expressas na Constituição já estavam em conformação e evolução por essa sociedade desde a Grã-Bretanha; ao passo que nos países da América Latina a imposição de regras formais em desconformidade com as praticadas pela sociedade acabou logrando resultados diferentes.

Derivado desta análise: a) North (1990) estabelece uma relação direta entre a existência de regras formais bem-sucedidas e a adequação de um ambiente cultural; e b) North (2003b) enfatiza que dificilmente ocorre a transposição da eficiência adaptativa das instituições. Em síntese, conforme exposto anteriormente, o processo histórico de conformação de uma matriz institucional - da qual decorre a dependência da trajetória - advém da percepção e atuação dos indivíduos e de seus sistemas de crenças que dão conformação às instituições (formais e informais) e a mecanismos de enforcement. ${ }^{26}$

\section{Conclusão}

Os estudos desenvolvidos no campo da NEI revigoraram o campo de pesquisas em diversas áreas: a) teoria econômica e do desenvolvimento;

26 Contudo, North (1995) afirma que nenhuma mudança é na prática totalmente revolucionária, posto que para a sua viabilização torna-se necessária a existência de normas sociais preexistentes que balizem e deem legitimidade às mudanças promovidas. 
b) historiografia econômica; c) desenvolvimento regional/local; d) planejamento, regulação, gestão e avaliação de políticas públicas. Passamos, nesta parte conclusiva, a listar algumas diretrizes de pesquisas - a título de exemplificação, portanto sem a pretensão de esgotar as possibilidades decorrentes - que podem ser adotadas a partir do estado da arte alcançado pela teoria das instituições e da mudança institucional de Douglass North, em especial no que se refere ao papel desempenhado pela cultura.

No campo da teoria econômica e do desenvolvimento, uma importante contribuição de seus estudos foi recolocar no seio do debate acadêmico, ou trazer para o centro do mainstream, a importância das instituições e dos aspectos culturais. Instituições importam, a cultura importa! Especificamente no que se refere aos aspectos culturais, abre-se uma desafiadora agenda de pesquisas que precisa ser adequadamente enfrentada.

O despertar da importância da cultura para o processo de desenvolvimento traz à baila a necessidade do alinhamento entre múltiplos conceitos frequentemente utilizados como intercambiáveis: cultura, hábito, ideologia e cosmovisão. Afinal, esses múltiplos conceitos, como utilizados por Douglass North em vários de seus trabalhos, são plenamente substituíveis? Ou existe uma agenda na teoria neoinstitucionalista de Douglass North que precisa ser enfrentada? Indo além, o que é efetivamente cultura? Qual a relação entre cultura, hábito, ideologia e religião? De que modo normas de comportamento derivadas culturalmente interagem com as regras formais? De que forma a cultura determina a cosmovisão de uma sociedade? A resposta para essas perguntas é estratégica se queremos avançar numa agenda que aprofunde os estudos da cultura como a chave para a compreensão da dependência de trajetória das sociedades.

Convém alertar, que esse é um terreno "espinhoso", posto ser um campo multidisciplinar, eivado de polêmicas conceituais, envolvendo antropólogos, sociólogos, economistas, entre outros. Contudo, North estabeleceu insights importantes, porém ainda deixou para uma próxima geração de pesquisadores a tarefa de melhor amarrar o conceito de cultura em sua teoria e alguns conceitos que ele frequentemente usava (ideologia, crenças, valores, por exemplo).

No campo de análise do desenvolvimento em uma perspectiva histórica, é importante o aprimoramento da compreensão sobre o processo de formação da matriz institucional de uma sociedade, aprofundando as respostas já desenvolvidas por North para algumas questões. Como se for- 
mam, evoluem e se modificam as instituições? De que forma os aspectos culturais impactam na definição dos direitos de propriedade? Como aspectos culturais podem influenciar a consolidação de uma dependência de trajetória? De que modo alterações em aspectos como ideologia e religião podem determinar ou alterar trajetórias sociais de longo prazo?

No campo da historiografia econômica abre-se uma agenda de pesquisa instigante, sobretudo no que se refere à revisitação de fatos históricos importantes para a conformação institucional das sociedades e, consequente, determinação de suas trajetórias de longo prazo. Essa agenda passa desde a influência cultural na sua formação originária, por seu processo de formação econômica, social e política, e por estudos sobre como rupturas institucionais alteraram trajetórias sociais de longo prazo. Um exemplo do leque de possibilidade aberto passa pelo estudo das rupturas institucionais como as revoluções socialistas em diversas partes do mundo, a ascensão do fascismo (Itália) e nazismo (Alemanha), a Revolução Meiji (Japão), a consolidação da Via Prussiana na Alemanha na Era de Bismarck (final do século XIX), a ascensão econômica da Coreia do Sul (em especial se comparada com a Coreia do Norte), as rupturas democráticas na América Latina, ou mesmo a queda do socialismo real no Leste Europeu. Neste ponto, convém destacar que há uma agenda crescente de pesquisas sendo desenvolvidas, por diversos pesquisadores, que, a partir de uma perspectiva (neo)institucionalista, estão estudando esses temas e outros correlacionados.

Outro exemplo de uma promissora agenda que pode ser enfrentada utilizando-se a teoria das instituições e da mudança institucional de North é a relação entre religião, cultura e desenvolvimento ou subdesenvolvimento. De que forma a Reforma Protestante interferiu no processo de consolidação do capitalismo? De que forma a migração dos puritanos calvinistas condicionou uma dinâmica de desenvolvimento diferenciada em alguns países? A cultura ibérica realmente conformou instituições indutoras do subdesenvolvimento na América Latina? É possível explicar desníveis de desenvolvimento num mesmo país, como o Brasil, em função das diferenças regionais do perfil migratório (cultura e religião), como o Norte/ Nordeste comparativamente ao Sul do país? Existem religiões indutoras do desenvolvimento e outras do subdesenvolvimento?

Alguns desses temas podem servir como elemento explicativo para o desnível do desenvolvimento territorial. Por que algumas cidades ou 
regiões adentram numa trajetória de desenvolvimento, criatividade, prosperidade econômica e social, e outras permanecem estagnadas ou até mesmo em declínio? A cultura econômica sedimentada em uma sociedade (cidade, região ou país) importa? Diferenças culturais ajudam a explicar diferenças locais e regionais de desenvolvimento em decorrência da conformação de instituições diversas? Casos como o Vale do Silício, Região de Badem-Wittenberg, Terceira Itália, País Basco, Vale dos Sinos no estado do Rio Grande do Sul ou o Vale Europeu em Santa Catarina podem ser estudados à luz de suas culturas diferenciadas que conformaram instituições indutoras de seu desenvolvimento?

Nas décadas de 1990 e 2000, observou-se na literatura especializada a eclosão de diversas nomenclaturas que se inseriam num amplo esforço, conduzido por diversos matizes teóricos, de tentar explicar a virtuosidade do desenvolvimento local de algumas experiências ao redor do mundo: clusters, Distritos Industriais Italianos ou Marshallianos, Arranjos Produtivos Locais, Sistemas Locais de Inovação, Parques Tecnológicos, Comunidades de Transbordamento, entre outros. Em geral, esses estudos consideraram, entre os seus fatores explicativos, a importância de uma forte institucionalidade subjacente, explícita ou implícita. Com base nisso, é possível revisitar esses estudos, ou essa agenda de pesquisa, a partir de um olhar institucional que amplie a importância da análise cultural nesses contextos.

Na prática uma parte considerável das tentativas de replicação dessas experiências exitosas, em outros contextos, por meio de políticas públicas indutoras, fracassou. Nesse sentido, é possível inferir que boa parte desse fracasso se deveu à não observância no processo de planejamento ou implantação dos aspectos culturais. Com isso, o nosso leque de questionamentos amplia-se. É possível replicar experiências de desenvolvimento ou de políticas públicas exitosas em qualquer contexto cultural? A não observância dos aspectos culturais e institucionais pode gerar simulacros?

A utilização do ferramental da teoria das instituições ao lado da observância adequada de aspectos culturais pode ser um caminho promissor para o aprimoramento do processo de planejamento, regulação, gestão e avaliação de políticas públicas. Em função de diferenças culturais, políticas públicas bem-sucedidas em determinados contextos podem fracassar noutros que possuem uma base cultural e institucional diferente. 
Isso realça a importância de se observar com maior atenção as questões culturais e institucionais das sociedades no processo de definição da agenda e do planejamento de políticas públicas. Essa observação também é válida para as fases de implementação e gestão de políticas públicas, nas quais os policy makers precisam estar atentos o tempo todo às peculiaridades culturais e institucional. Um exemplo disso é o controle social, que deverá ocorrer mais fortemente numa comunidade como maior senso de participação na res pública.

A regulação de políticas públicas também requer atenção especial aos aspectos institucionais e culturais, principalmente na análise do poder de enforcement. Ademais, é necessário avançar em estudos que possam estabelecer o real impacto das questões culturais em temas como a corrupção. Afinal, existem culturas mais propensas à corrupção? Até que ponto a corrupção impacta os custos de transação de uma sociedade e tornam o ambiente econômico mais adverso? A necessidade de ampliação das instituições formais, de ampliação da regulação do Estado e de ampliação dos mecanismos de governança e controle, ao final das contas, amplia o custo de transação para operação nessa sociedade? Em caso positivo, quais as consequências para o processo de desenvolvimento de longo prazo?

No processo de avaliação de políticas públicas, da mesma forma, é de fundamental importância a inclusão da correlação entre os aspectos culturais e institucionais com os resultados alcançados, portanto, com o sucesso, fracasso, ou necessidade de ajustes da política.

Em síntese, a teoria das instituições e da mudança institucional, e sua ênfase na cultura como a chave para a compreensão da dependência de trajetória de uma sociedade, revigora toda a análise do ciclo de políticas públicas. Certamente, esta é uma tarefa desafiadora, sobretudo, pela difícil modelagem das instituições informais e da cultura.

Indiscutivelmente, a teoria das instituições e da mudança institucional de Douglass North revigorou a agenda de pesquisas em diversas áreas, lançando na atual geração inúmeros questionamentos que requisitam pesquisadores atentos para as conexões existentes: a) os modelos cognitivos individuais, os modelos mentais compartilhados, a cultura de uma sociedade, e a conformação e evolução de suas instituições; e b) a teoria econômica e do desenvolvimento, a historiografia econômica, os estudos sobre o desenvolvimento regional/local, e o processo de planejamento, regulação, gestão e avaliação de políticas públicas. 


\section{Referências}

ABRAMOVAY, Ricardo. Desenvolvimento e instituições: a importância da explicação histórica. In: ARBIX, Glauco; ZILBOVICIUS, Mauro; ABRAMOVAY, Ricardo. Razões e ficções do desenvolvimento. São Paulo: UNESP/EDUSP, 2001.

ACEMOGLU, Daron; ROBINSON, James. Por que as Nações fracassam: as origens do poder, da prosperidade e da pobreza. Rio de Janeiro: Elsevier, 2012.

AZEVEDO, Bonnie. Uma análise antropológica de Douglass North (1973-2009): indivíduo, racionalidade, cultura e instituições. Tese (Doutorado em Políticas Públicas, Estratégias e Desenvolvimento) - Programa de Pós-Graduação em Políticas Públicas, Estratégias e Desenvolvimento, Instituto de Economia, Universidade Federal do Rio de Janeiro (UFRJ), Rio de Janeiro, 2015.

BOYD, Robert; RICHERSON, Peter J. Culture and the Evolucinary Process. Chicago: University of Chicago Press, 1985.

CHANG, Há-Joon. Chutando a escada: a estratégia de desenvolvimento em perspectiva histórica. São Paulo: Editora UNESP, 2004.

DENZAU, Arthur T.; NORTH, Douglass C. Shared Mental Models: Ideologies and Institutions. Kyklos 47, Fasc. 1 (3-31), 1994.

FIANI, Ronaldo. Estado e economia no institucionalismo de Douglass North. Revista de Economia Politica, v. 23, n. 2 (90), abr.-jun. 2003.

GALA, Paulo. Teoria e retórica em Douglass North: subsídios para uma análise de sua contribuição. Dissertação (Mestrado) - Departamento de Planejamento e Análise Econômica da Escola de Administração de Empresas de São Paulo (EAESP)/FGV, São Paulo, 2001.

GALA, Paulo. A teoria institucional de Douglass North. Revista de Economia Política, v. 23, n. 2 (90), abr.-jun. 2003a.

GALA, Paulo. A retórica na economia institucional de Douglas North. Revista de Economia Politica, v. 23, n. 2 (90), abr.-jun 2003 b.

HODGSON, Geoffrey H. Lock-in and Chreodic Development. In: HODGSON, G.; SAMUELS, W.; TOOL, M. (Ed.). The Elgar Companion to Institucional and Evolutionary Economics. Hants: Eduard Elgar, 1994.

HUNTINGTON, Samuel P. A importância das culturas. In: HUNTINGTON, Samuel P. (Org.) A cultura importa: valores que definem o progresso humano. Rio de Janeiro: Record, 2004.

LANDES, David. Quase toda a diferença está na cultura. In: HARRISON, Lawrence E.; HUNTINGTON, Samuel P. (Org.). A cultura importa: valores que definem o progresso humano. Rio de Janeiro: Record, 2004.

LOPES, Herton Castiglioni. Instituições e crescimento econômico: os modelos teóricos de Thorstein Veblen e Douglass North. Rev. Econ. Polit., v. 33 n. 4, São Paulo, Oct./Dec. 2013 Disponível em: <www.scielo.br/scielo.php?pid=S0101-31572013000400004\&script=sci_ arttext>. Acesso em: 22 mar. 2019.

NORTH, Douglass C. Structure and Change in Economic History. New York: W. W. Norton, 1981. 
NORTH, Douglass C. Institutions and Economic Growth: A Historical Introduction. Word Development, v. 17, n. 9: 1.319-1.332, Sept., 1989.

NORTH, Douglass C. Instituions, Institutional Change, and Economic Performance - Political E of Instituions and Decisions. Cambridge: Cambridge University Press, 1990.

NORTH, Douglass C. Institutions. Journal of Economic Perspective, 5: 97-112, 1991.

NORTH, Douglass. The New Institutional Economics and Development. Washington University in St. Louis, 1992.

NORTH, Douglass C. Five Propositions about Institutional Change. Munich: University Library of Munich, 1993. Disponível em: <https://ideas.repec.org/p/wpa/wuwpeh/9309001. html>. Acesso em: 12 abr. 2019.

NORTH, Douglass C. Institutional Change: A Framework of Analyses. University Library of Munich, Germany, revised 14 Dec. 1994a. Disponível em: <https://ideas.repec.org/p/ wpa/wuwpeh/9412001.html>. Acesso em: 03 abr. 2019.

NORTH, Douglass C. El desempeño económico a lo largo del tiempo. El Trimestre Económico, v. LXI (4), edição 244, 567-583, 1994 b.

NORTH, Douglass C. The New Institutional Economics and Third World Development. 1995. Disponível em: <http://www2.econ.iastate.edu/tesfatsi/NewInstE.North.pdf>. Acesso em: 01 out. 2019.

NORTH, Douglass C. The Role of Institutions in Economic Development: Gunnar Myrdal Lecture. United Nations Publications, 2003a.

NORTH, Douglass C. Understanding the Process of Economic Change. In: Forum Series on the Role of Institutions in Promoting Economic Growth, 2003b. NORTH, Douglass C. Understanding the Process of Economic Change. Princeton/Oxford: Princeton University Press, 2005.

NORTH, Douglass. Instituições, mudança institucional e desempenho econômico. São Paulo: Três Estrelas, 2018.

NORTH, Douglass C.; MANTZAVINOS, Chrystostomos; SHARIQ, Syed. Learning, Institutions, and Economic Performance. Perspectives on Politics, v. 2, n. 1, pp. 1-19, 2004. Disponível em: <https://philarchive.org/archive/MANLIA-3>. Acesso em: 12 abr. 2019.

NORTH, Douglass C.; THOMAS, Robert. The Rise of the Western Word: A New Economic History. Cambridge: Cambridge University Press, 1973.

NORTH, Douglass C.; WALLIS, John Joseph; WEINGAST, Barry R. A Conceptual Framework for Interpreting Recorded Human History. National Bureau of Economic Research, 2006. Disponível em: <http://www.international.ucla.edu/cms/files/north_wallis_weingast. pdf>. Acesso em: 14 abr. 2019.

PORTER, Michel E. Atitudes, valores, crenças e a microeconomia da prosperidade. In: HARRISON, Lawrence E.; HUNTINGTON, Samuel P. (Org.). A cultura importa: valores que definem o progresso humano. Rio de Janeiro: Record, 2004.

ROBLES, Gustavo A. Prado. El pensamiento económico de Douglass C. North. Laissez-Faire, n. 9, 13-32, sept. 1998.

RUTHERFORD, Malcolm. Institutions in Economics: The Old and the New Institutionalism. Cambridge: Cambridge University Press, 1994. 
SIMÕES, André. Instituições e desenvolvimento econômico: os contrastes entre as visões da Nova Economia Institucional (NEI) e dos neoinstitucionalistas. Ensaios FEE, Porto Alegre, v. 35, n. 1, p. 33-54, jun. 2014.

STORPER, Michael. Las economias regionales como activos relacionales. Cadernos IPPUR, Rio de Janeiro, Ano XIII, n. 2, 1999.

STRACHMAN, Eduardo. Política industrial e instituições. Tese (Doutorado) - Instituto de Economia da Universidade Estadual de Campinas, 2000.

\section{Sobre o autor}

Eduardo José Monteiro da Costa - ejmcufpa@gmail.com

Universidade Federal do Pará, Belém, Pará, Brasil.

ORCID: https://orcid.org/0000-0001-7990-6232.

O autor agradece a Faculdade de Economia e ao Instituto de Ciências Sociais e Aplicadas da Universidade Federal do Pará pelo apoio ao desenvolvimento do projeto de pesquisa "Economia e Religião: A Socioeconômica do Desenvolvimento Capitalista" que propiciou a elaboração deste artigo. Ademais, o autor agradece aos comentários e recomendações do parecerista anônimo e do editor da revista que foram importantes para o aprimoramento da versão final do artigo.

\section{Sobre 0 artigo}

Recebido em 28 de outubro de 2019. Aprovado em 03 de março de 2020. 